See Article page 79.

\section{Commentary: You will see them again-sooner or later}

\author{
Karthik Ramakrishnan, MD, and Can Yerebakan, MD
}

Supravalvar aortic stenosis (SAS) is the most significant cardiovascular manifestation of Williams-Beuren syndrome. ${ }^{1}$ Clinically significant SAS has a wide range of phenotypic manifestations. ${ }^{2}$ The disease process affecting the aorta is a spectrum ranging from discrete localized thickening of the sinotubular junction to a more extensive involvement of the coronary ostia, ascending aorta, the aortic arch and its branches, the descending aorta, or rarely the renal arteries or intracranial arteries. ${ }^{1}$ Discrete and milder forms of SAS can be managed with any of the well-established surgical techniques with good outcomes. ${ }^{3}$ Diffuse forms of the disease present a challenging surgical entity. Mild SAS can improve with time or even resolve in a subset of children (about 13\%). ${ }^{4}$ However, moderate or more severe forms require surgical intervention for hemodynamically significant SAS. An estimated $37.5 \%$, $48 \%$, and $65 \%$ of these patients require intervention at 5 , 10 , and 20 years, respectively. ${ }^{5}$

In this issue of the Journal, Katahira and colleagues ${ }^{6}$ report the surgical management of complex recurrent SAS with involvement of the ascending aorta and the brachiocephalic artery, with coexisting aortic valve disease. Their patient underwent Doty's procedure (pantaloon patch 2 sinus repair) at the age of 6 years and was regularly followed up. At the age of 41 years, he was diagnosed with severe aortic valve stenosis and recurrent SAS extending into the

\footnotetext{
From the Department of Cardiovascular Surgery, Children's National Heart Institute, Children's National Hospital, Washington, DC; and Department of Surgery and Pediatrics, The George Washington University School of Medicine and Health Sciences, Washington, DC.

Disclosures: The authors reported no conflicts of interest.

The Journal policy requires editors and reviewers to disclose conflicts of interest and to decline handling or reviewing manuscripts for which they may have a conflict of interest. The editors and reviewers of this article have no conflicts of interest.

Received for publication Dec 8, 2019; revisions received Dec 8, 2019; accepted for publication Dec 12, 2019; available ahead of print Feb 20, 2020.

Address for reprints: Can Yerebakan, MD, Department of Cardiovascular Surgery, Children's National Heart Institute, Children's National Hospital, The George Washington University School of Medicine and Health Sciences, 111 Michigan Ave NW, Washington, DC 20010 (E-mail: cyerebakan@childrensnational.org). JTCVS Techniques 2020;3:83-4

2666-2507

Copyright (C) 2020 The Authors. Published by Elsevier Inc. on behalf of The American Association for Thoracic Surgery. This is an open access article under the CC BY-NCND license (http://creativecommons.org/licenses/by-nc-nd/4.0/).

https://doi.org/10.1016/j.xjtc.2019.12.010
}

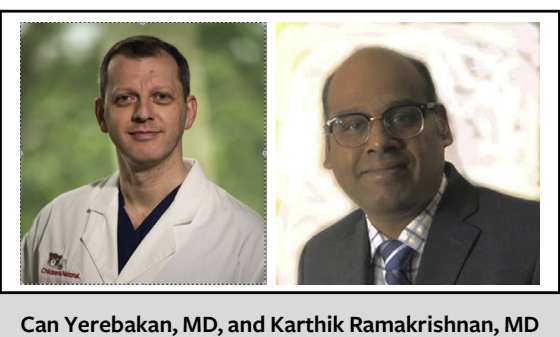

CENTRAL MESSAGE

Aortic pathology can recur late after initial repair in WilliamsBeuren syndrome. Life-long follow-up of these patients is necessary, with a potential for redo surgical repair.

proximal aortic arch and the origin of the brachiocephalic artery. The patient was successfully treated with a mechanical aortic valve replacement and ascending aortic replacement with hemi-arch augmentation to include enlargement of the stenosed origin of the innominate artery with an excellent outcome.

The nicely presented case highlights some critical aspects of the modified history of SAS. The operative mortality for primary repair of discrete SAS is less than $1 \%$, with 5-year survival approaching $96 \%{ }^{3}$ However, the freedom from reintervention for left-sided obstructive lesions is $79 \%$ at 5 years and $70 \%$ at 10 years. This case report further illustrates that recurrences can occur late after initial intervention and can assume a diffuse form. Therefore, patients with repaired SAS should be on close and probably life-long follow-up to detect recurrences.

The surgical strategy described by the authors appears to be easily reproducible and follows the basic general principles described to protect the end-organs during complex aortic arch surgery. The conduct of cardiopulmonary bypass in these situations is critical to achieve a satisfactory result. Deep hypothermic circulatory arrest, selective cerebral perfusion, and whole-body perfusion are some of the strategies that have been extensively used and studied. Each one of them has their own advantages and disadvantages, and the choice of strategy depends on the preference and expertise of the particular center. The favorable outcome achieved in this patient is a testament not only to the surgical skills but also to the organization and planning of the entire team involved in the operation. We thank the authors for their contribution. 


\section{References}

1. Pober BR. Williams-Beuren syndrome. N Engl J Med. 2010;362:239-52.

2. Yuan M, Deng L, Yang Y, Sun L. Intrauterine phenotype features of fetuses with Williams-Beuren syndrome and literature review. Ann Hum Genet. 2020;84: 169-76.

3. Scott DJ, Campbell DN, Clarke DR, Goldberg SP, Karlin DR, Mitchell MB. Twenty-year surgical experience with congenital SAS. Ann Thorac Surg. 2009; $87: 1501-8$.
4. Collins TR, Kaplan P, Somes GW, Rome JJ. Long-term outcomes of patients with cardiovascular abnormalities and Williams syndrome. Am J Cardiol. 2010;105: 874-8.

5. Cha S, Song M, Lee S, Kim GB, Kwak JG, Kim WH, et al. Long-term cardiovascular outcome of Williams syndrome. Congenit Heart Dis. 2019;14:684-90.

6. Katahira S, Sugimura Y, Lichtenberg A, Akhyari P. Late reoperation after proximal repair of supravalvular stenosis for diffuse form of Williams-Beuren syndrome. J Thorac Cardiovasc Surg Tech. 2020;3:79-81. 